\title{
Limiting Taxpayer "Puts"-An Example from Central Counterparties
}




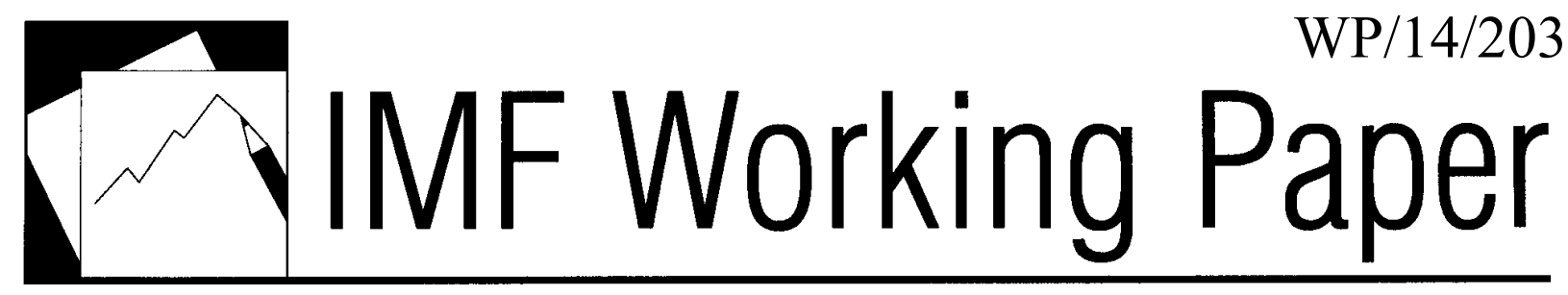

Limiting Taxpayer "Puts"-An Example from Central Counterparties

Manmohan Singh 


\title{
IMF Working Paper
}

Monetary and Capital Markets Department

\section{Limiting Taxpayer "Puts"—An Example from Central Counterparties" Prepared by Manmohan Singh}

Authorized for distribution by Karl Habermeier

November 2014

\section{This Working Paper should not be reported as representing the views of the IMF.} The views expressed in this Working Paper are those of the author(s) and do not necessarily represent those of the IMF or IMF policy. Working Papers describe research in progress by the author(s) and are published to elicit comments and to further debate.

\begin{abstract}
Nonbanks such as central counterparties (CCPs) are a useful lens to see how regulators view the role of the lender-of-last-resort (LOLR). This paper explores the avenues available when a nonbank failure is likely, specifically by considering the options of keeping CCPs afloat. It is argued that CCPs have, by regulatory fiat, become "too important to fail," and thus the imperative should be greater loss-sharing by all participants that better align the distribution of risks and rewards of CCPs, the clearing members and derivative end-users. In the context of LOLR, the proposed variation margin gains haircut $(\mathrm{VMGH})$ is discussed as a way of limiting the taxpayer put.
\end{abstract}

JEL Classification Numbers: G21, G28, F33, K22, G18, G15

Keywords: Lender-of-last-resort; central counterparties; variation margin gains haircut Author's E-Mail Address: msingh@,imf.org

\footnotetext{
${ }^{1}$ The paper has benefited from various discussions with official sector and market participants, on the condition of anonymity. The author wishes to thank Stijn Claessens, Miguel Savastano, and Karl Habermeier for several suggestions. All remaining errors are mine.
} 


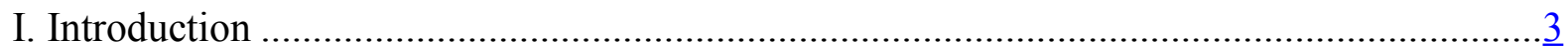

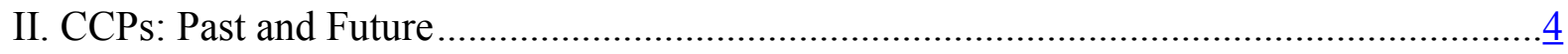

III. Some Loss-Allocation Choices ..........................................................................

IV. Variation Margin Gains Haircut (VMGH) ..........................................................

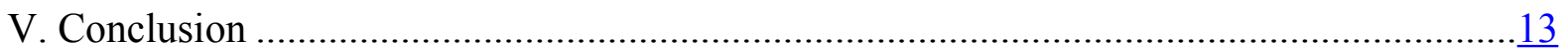

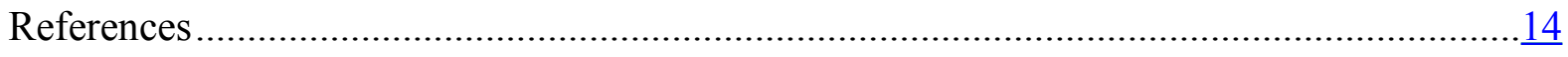

Figures

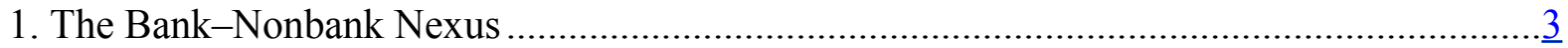

2. A Hypothetical "Waterfall" Situtation ....................................................................

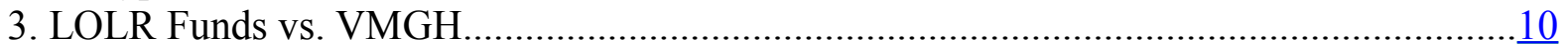

Box

Central Bank Liquidity (when there is no uncapped VMGH) .......................................12

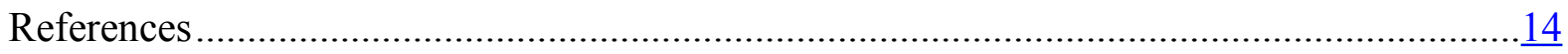




\section{INTRODUCTION}

Banking and non-banking activities carried on by banks are often closely intertwined and legally difficult to disentangle, especially for systemically important banks (SIBs). Even though SIBs are normally classified as "depository" institutions, a significant portion of their exposures may be non-deposit related - in some instances over 90 percent (e.g., Goldman Sachs, Morgan Stanley). ${ }^{2}$ When SIBs run into trouble and require government support, it will often be because of their nonbanking activities. However, nonbanks, such as hedge funds, asset managers, insurers, pension funds and central counterparties (CCPs), do not overlap with SIBs (see Figure 1). Thus, ex ante, there is little economic justification for the argument that those nonbanks should receive taxpayer support, if taxpayer support is justified as protection of deposits.

At the same time, global regulators have already labeled some insurers as systemically important. CCPs have also garnered special status as financial market infrastructures (FMIs) - or financial market utilities (FMUs), as they are termed in the United States (U.S.). The bank-nonbank nexus is vital to understanding the financial plumbing that supports financial stability. Despite some earlier arguments that moving over-the-counter (OTC) derivatives to CCPs was not an ideal solution for financial stability, the political reality is that more complex CCPs are here to stay (Singh, 2010). Nonbanks such as CCPs are perhaps the most useful lens to see how regulators rationalize the access of nonbanks to public funds. The interconnectedness inherent in the function of CCPs, coupled with the surge in the variety and volume of products subject to mandatory clearing under the G20 agenda, implies an even greater likelihood that the failure of a CCP would have severe systemic consequences.

Figure 1. The Bank-Nonbank Nexus

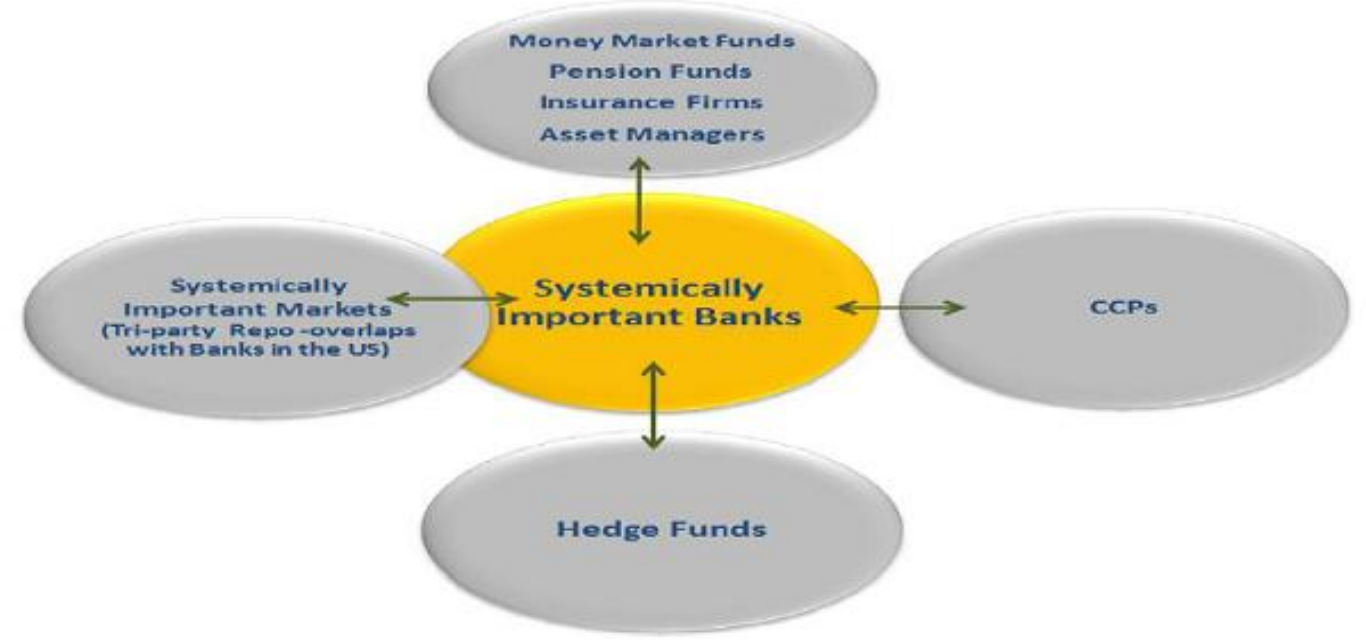

Source: Singh, 2012.

\footnotetext{
${ }^{2}$ Such deposits are "insured" and are increasing by sweeping excess client cash from broker-dealer accounts.
} 
Recognition of the risk that CCPs may be "too important to fail," or systemically important, has led to efforts at both the international and national levels to design specific statutory frameworks for their recovery and resolution, with the stated objective of minimizing the amount of public funds that could be needed for their rescue (Tucker, 2013). The revised BCBS-IOSCO Principles for Financial Infrastructures include new stringent requirements for CCP operations, risk management and supervision. While these principles aim at preventing a CCP failure, the complexity and uncertainty of clearing the multitude of instruments now accepted by CCPs means that there remains a residual risk of CCP failure. The interests of safeguarding financial stability through preserving the continuity of critical services dictates that the recovery and resolution procedure for those entities must be relatively swift and simple and arithmetically supportable. ${ }^{3}$ In order to safeguard financial stability, a mismatch in the balance sheet of a CCP has to be arrested at a much earlier stage than would be possible under a regular corporate insolvency framework (Gibson, 2013).

This paper is based on the premise that it is unlikely that any systemically important CCPs will be allowed to fail. Financial stability considerations will quickly generate pressures for some solution, e.g., supplementary funding such as additional assessments, or access to central bank funds, or haircuts on all users of OTC derivatives etc. Discussions of such matters as a selective or complete tear-up of contracts, bridges (Title II of the Dodd-Frank Act), the portability of contracts to other CCPs and the winding-up of CCPs are not realistic in the OTC derivative space. This is unchartered territory, and the past history of CCP failures and bailouts has not been associated with CCPs that were primarily derivative entities. $^{4}$

The exemption from the stay, or "safe harbor" provision that has been granted to qualifying financial contracts (QFCs) in most major jurisdictions (e.g., the U.S. Bankruptcy Code and the EU directive on Financial Collateral Arrangements) prohibits any supervisory intervention that could delay, override or modify the enforcement of financial collateral arrangements. Their continuity is deemed to be paramount and there is not much in the new regulations such as Dodd-Frank or Basel III that has changed the protected QFC status enjoyed by OTC derivatives (Summe, 2012).

\section{CCPs: Past And Future}

As noted the interconnectedness and widening systemic footprint of CCPs has led to efforts to design special statutory frameworks to manage their possible failure. It is critical, however, to assess whether those efforts are in the right direction. This is not to dispute the possibility of a CCP becoming insolvent - the near-failures of the French Caisse de

\footnotetext{
${ }^{3}$ In this context 'arithmetically supportable' means that the central bank or national treasury will have sufficient liquid resources or credit to cover any CCP losses not met by the assets available in the CCP default waterfall at the time of imminent failure.

${ }^{4}$ Some may be sympathetic to full tear-ups (e.g., ISDA et al, 2013); however the fundamental premise of moving OTC derivatives to CCPs via novation of original contract was no reversal back to original parties.
} 
Liquidation in 1974, the Kuala Lumpur Commodities Clearing House in 1983, and the Hong Kong Futures Exchange in 1987 are stark reminders.

A key feature that differentiates CCPs from other financial institutions, as well as from FMIs, is the extent of loss absorption that is wired into their legal structure (which vary across countries), and risk management policies. CCPs are designed to pre-fund liquidation of clearing member positions through initial margin and maintain surplus cover of exposures through periodic variation margin so that the CCP does not take market risk or credit risk except under extreme scenarios. Extreme scenarios are then covered through default fund and equity provision. Thus, CCPs typically do not hold as much "conventional" capital (in the form of equity or equity-like capital instruments) as other financial institutions to provide a loss-absorbing buffer. However due to mandatory clearing, CCPs are now taking on positions in instruments that are less liquid and exposed to less predictable price volatility. As a result the classic tools for managing CCP credit and market risk may not perform as well as they have historically, leaving a residual risk that a CCP may exhaust its waterfall of default resources in managing the failure of a significant clearing member. In this light, it might be argued that CCPs have (or will) become, by regulatory fiat, "too important to fail". 5

We may question, however, what exactly the winding-up of a CCP, or tear-up contracts, or "bridging the defaulting members' portfolio," or portability from one CCP to another would look like given the nature of its assets and liabilities. Previous episodes of CCP stress (including the Chicago Mercantile Exchange in 1987), offer little guidance, since those CCPs balance sheets did not have many derivatives. At present, jumps in the derivatives market can have huge impact on CCPs positions, as the "in" and "out" of the money positions are in the trillions of US dollars (BIS, 2014). Margin calls can stress market and credit liquidity as market participants struggle to finance the variation margin assessed against volatile movements in exposure valuations. Requiring all the participants in a CCP (owners/shareholders, clearing members, and end-users) bear the costs will have an impact on other financial entities-i.e., asset managers, pension funds, insurance companies and others. Some argue that this impact on end-users is sufficient to justify the use of public money to rescue CCPs. We think this argument is weak because end-users only are a subset of taxpayers - and the subset can be small or large, depending on the institutional set-up or investment guidelines/regulations of a country.

To the extent that clearing members (CMs) bear the burden of recapitalizing the CCP by absorbing losses and replenishing the default fund, the question arises whether changes to the ownership and governance structure of CCPs are needed? That is, participants should share in owner-shareholder rights such that the mutualization of risks and losses by participants is better correlated with the mutualization of rewards. One way to achieve this might be to

\footnotetext{
${ }^{5}$ It should be noted that due to regulatory demand, collateral needs will further "interconnect" the financial system (and moving derivatives to CCPs was supposed to break the interconnectedness). In general, central banks, sovereign wealth funds and long-term asset managers desire collateral that is of low volatility, but not necessarily highly liquid. These entities should be net providers of liquidity in the financial system. On the other side are banks, hedge funds and mutual funds that have a dramatically shifting need for liquid and good collateral. So a market for collateral upgrades and transformations - in theory - could work.
} 
require user-ownership of CCPs. While some CCPs are currently structured this way, it is not mandated by law, although it has received official support in certain jurisdictions such as the U.K., which alludes to "...strengthened risk management, fostered by user-ownership and 'not-for-profit' arrangements" (Bank of England, 2010). In some cases, CCPs are owned partly by users and partly by for-profit exchanges (for example, LCH Clearnet Limited). In most cases, however, CCPs are owned entirely by exchanges or independent shareholders, and run for profit (for example, ICE).

Should CCPs be given a public-interest utility status, becoming entirely user-owned, not-forprofit operations? As discussed earlier, treating CCPs as utilities is not appropriate unless they were to cover the full spectrum of "economic rents" (Singh, 2013). ${ }^{6}$ Moreover, it will be difficult for CCPs to attract investment, and be a viable business model, in the absence of a statutory or de facto monopoly (for example, SWIFT in relation to financial messaging).

Avoiding taxpayer bailouts seems to be well supported by most jurisdictions and is the basic philosophy underlying the principles for CCPs. Regulatory proposals suggest CCPs should never get to the resolution point if all derivative users and CCPs know the cost ex ante and then decide whether to pay up front (i.e., via the waterfall), or ex post (in the form of cash calls, or haircutting "in the money positions"-see Section IV). The next section looks into some choices that are robust enough and will likely preclude relying on taxpayer money.

\section{Some LoSS-Allocation CHOICES}

In theory a CCP is not supposed to take credit risk or market risk on the positions it holds as all exposures should be pre-funded by adequate initial margin, with any residual loss on liquidation adequately covered by default facilities. Variation margin assessments on a daily basis, or even intra-day, eliminate the exposure arising from market price volatility. As a result of these risk management principles, CCPs do not rely on debt (or equity) financing in the same way as financial institutions, or other corporate entities. From a political and economic perspective, it is desirable that any default losses in a CCP be absorbed in part by all users of the CCP. Furthermore, a distinction should be drawn between different types of participants, in particular clearing members, (as direct participants) and their clients (as indirect participants).

A default arises when a clearing member $(\mathrm{CM})$ fails to meet a variation margin call in a timely manner. In the absence of the variation margin (VM) payment, the CCP assumes the risk exposure of movements in market prices to non-defaulting clearing members. In that case, the CCP will no longer have a matched book and will be exposed to changes in the market value of its unmatched positions. In order to return to a matched book, the CCP will need to close out its unmatched positions, for example by entering into offsetting/hedging

\footnotetext{
${ }^{6}$ Comparing CCPs to utilities is problematic, given that the e business model currently prevalent among CCPs has led to "niche franchises." For that reason as all "economic rents" earned from an OTC derivative contract s are fragmented across origination fee, netting and clearing fee, and thus unlikely to be calculated precisely and transparently ex-ante.
} 
transactions and/or by auctioning the positions to non-defaulting CMs. If market prices move against the $\mathrm{CCP}$ during this period the $\mathrm{CCP}$ may incur losses. The CCP's primary protection against this contingent market risk is the initial margin (IM) that it collects from CMs. The size of the IM requirement is set with the aim of ensuring that it is large enough to meet the loss that the CCP may incur between the point that a CM defaults (and so ceases to provide $\mathrm{VM}$ ), and the point at which the CCP hedges or auctions the defaulting CM's position and returns to a matched book.

In case the margin that the CCP holds from the defaulter is not sufficient to meet the loss, the CCP maintains a prefunded default waterfall (i.e., default/guarantee fund) to which all CMs are required to contribute, and is an approximate relation to the amount of risk that each $\mathrm{CM}$ brings to the CCP). These funds serve to mutualize the residual loss among the surviving CMs (IMF's GFSR, 2010). However, waterfalls are not transparent. The recent example of Hanmag Securities, a futures broker in Korea that defaulted in December 2013, is pertinent here. The experience from the Korean clearing house KRX suggests that the fine print matters - KRX capital came after the non-defaulting members' default fund contributions (SecFin Monitor, 2014)

To the extent that prefunded default resources are prudently calculated, they will be sufficient to preclude the closure of a CCP due to uncovered losses. Consistency with the CPSSIOSCO recommendations requires the allocation of so-called "end-of-the-waterfall" losses to be written into CCP rules, if they are not already. ${ }^{7}$ This ensures that the allocation of all potential losses is established ex ante in the CCP's rulebook. Mandatory end-of-the-waterfall loss-allocation rules have received support in the U.K. (Elliot 2013).

A further option for loss allocation is haircutting variation margin so that clearing members on the profitable side of market movements (i.e., opposite the loss-making positions held for the defaulting clearing member) do not receive the entirety of the profits expected. From a legal perspective, margin haircutting needs to be limited to VM under existing U.S. and European Union (EU) laws. EMIR (European Market Infrastructure Regulation) prohibits CCPs from using IM posted by non-defaulting clients/members to cover losses arising from the default of another CM. Similarly, the IM is bankruptcy-remote/segregated under U.S. law, and thus this collateral is off-limits and cannot be part of an insolvent estate; and it is also unlikely to be rehypothecated. Additionally, while the EMIR acknowledges that a nondefaulting $\mathrm{CM}$ may be required to provide additional funds to the $\mathrm{CCP}$ in the event of the default of another CM, it establishes a principle of limited liability for CMs that appears to

\footnotetext{
${ }^{7}$ The default waterfall refers to the financial safeguards available to the CCP to cover losses arising from a CM default ("default losses") and the order in which they may be spent, while end of the waterfall refers to situations following the exhaustion of all such financial safeguards. There are also situations where a CCP's financial safeguards and any minimum CCP capital requirements may be exhausted that are unrelated to a CM default ("non-default losses"). Such situations including any recovery or resolution mechanisms should be viewed differently from those that would apply for default losses (from letter to CPSS/IOSCO from ISDA et al.)
} 
preclude the possibility of uncapped cash calls. Also, under proposed Basel III regulations, bank capital requirements will be hard to calculate if there are uncapped liabilities. ${ }^{8}$

In summary, if a CCP loss allocation options allows for targeted haircuts, then, after default by one or more CMs, any jumps or windfall gains (i.e., an increase in in-the-money positions) may not be paid in full. In other words, those gains would be subject to a haircut. The larger the haircut, the smaller the recourse to government will be needed to keep the CCP operational.

\section{VARiation Margin Gains Haircut (VMGH)}

Recent ISDA margin surveys and BIS studies suggest that, about US\$3.8 trillion of collateral was used as margins (ISDA 2013). Adjusting for double counting of in-the-money and outof-the-money positions, there is about US\$1.9 trillion of collateral that is in-the-money. However, at present, collateral is continuously reused (at least at present by the dealers). Adjusting for a re-use rate of between 2 and 3, collateral that is in in-the-money positions may be in the order of US\$700-900 billion (Singh 2013). ${ }^{9}$ These estimates are similar on magnitude to the figures reported in the financial statements of the top 10-15 banks active in OTC derivatives market. ${ }^{10}$ Thus, the sizable under-collateralization in the OTC derivatives market which should manifest itself in the waterfalls of the CCP world.

However, under-collateralization in this market since Lehman remains in the US\$3-5 trillion range (BIS, 2014). As the clearing mandate will result in higher margins under CCPs' control, there may be sizable funding needs if a $\mathrm{CCP}$ is in trouble. The distinction between liquidity needs of a CCP or solvency problems of a CCP is blurred during periods of stress. A variation margin gain haircuts, however, helps to separate the two states (see Figure 2, last rectangle). Unlike default waterfalls, VMGH has the effect of funding CCP losses by taking profits from both CMs and indirect participants (or end-users) with positions in-the-money. Since CCPs generally face CMs (and not end-users), CCPs cannot directly haircut the end user. So either there is an agreed 'pass through' of haircut from CM to end-user, in line with the latter's VM gain positions, or since CM benefits from netting (and collateral reuse) of pooled end-user positions, CM could explicitly commit to assuming all haircuts. Alternately,

\footnotetext{
${ }^{8}$ See pages $49-50$ of this link on uncapped liabilities http://www.esma.europa.eu/system/files/2014297 qa_vii_on_emir_implementation_20_march_14_0.pdf
}

Pages 50-52 of above link clarifies that while EMIR does not allow the haircutting of non-defaulting CM's initial margin, (uncapped) variation margin haircutting is compliant with EMIR.

${ }^{9}$ Collateral reuse (or velocity) has decreased from about three since Lehman's demise to about two at present; this decline has been driven by many factors including QE (that silos good collateral), regulations that limit reuse of collateral (e.g., initial margin with CCPs), supply of good collateral from security lenders stemming from counterparty risk within the financial system, and reduced balance sheet space with banks/dealers to move collateral around. However, there is another view (in regulatory circles) that too much collateral reuse/high velocity may lead to sharp unwinds of collateral chains during a crisis.

${ }^{10}$ See, Heller and Vause (2013). 
CMs can charge end-users for this 'insurance' via an ongoing fee. Larger end-users would be reasonably well placed to negotiate more favorable terms with their clearing agents than smaller end users. ${ }^{11}$ VMGH thus forces all users to look for a market solution, absent which CCPs are closer to LOLR funds - a "put" stemming from reshuffling OTC derivatives from banks to CCPs; or resolution that is not in the interest of CMs, end-users or CCPs. ${ }^{12}$

Figure 2. A Hypothetical "Waterfall” Situation

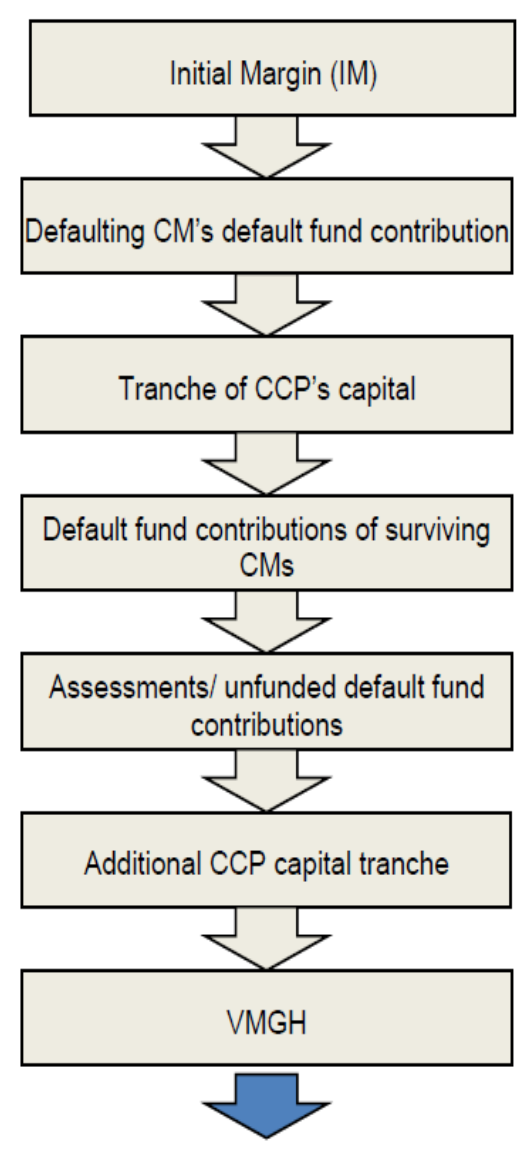

This might be securities or cash ${ }^{*}$. Main "defence" against default (in $99 \%+$ cases IM should be sufficient to cover the loss)

Usually cash - defaulter's default fund contribution used before those of non defaulting $\mathrm{CMs}$

Tranche of CCP's capital (CCP 's "skin in the game")

Default fund contributions of non defaulting $\mathrm{CMs}$

Most CCPs can call surviving members for a further unfunded DF contribution (an "assessment") that may be at defined multiples of the funded DF contribution

Can mitigate moral hazard in which the CCP under-protects cleared positions with either insufficient margins or other waterfall protections because it assumes it will be protected from insolvency

CCP Recovery Rules - Haircutting of unpaid VM as a means to allocate losses beyond those resources further up the waterfall, both (i) during default management prior to auction and (ii) as part of assurance of funds to transfer portfolio or replace positions at the auction settlement price

\begin{abstract}
* As an aside, whether securities collateral is likely to be capable of consideration as "bankruptcy remote" from the CCP remains uncertain and will depend on insolvency law and CCP-specific assessments; cash collateral is expected not to be "bankruptcy remote" from the CCP.
\end{abstract}

Source: ISDA (August, 2013), "CCP Loss Allocation at the End of the Waterfall."

\footnotetext{
${ }^{11}$ This may be a reason why large clients negotiating position may force CMs to assume VMGH and then negotiate a capped VMGH with CCPs and regulators, rather than uncapped VMGH. However, the latter route minimizes the taxpayer "put."

${ }^{12}$ See "Recovery of Financial Market Infrastructures-Final Report" October 2014.
} 
Assume CMs pass on the VMGH to the end user, one way or the other. As an illustration, let's assume that the positions in a CCP are highly asymmetric, with two big players (an "Asset Manager" like Blackrock with trillions in AUM, and a large hedge fund with \$10-15 billion in AUM) that are "in the money" and "out of the money," respectively, by US $\$ 50$ billion as a result of a jump event in the OTC derivatives market, while the other n-2 players are neutral to the jump. ${ }^{13}$ If the large hedge fund cannot meet the VM stemming from their "out of the money" position to their CM (who in turn has to post to a CCP), then any shortfall $\mathrm{x} \leq \$ 50$ billion to Blackrock will not be paid; and the hedge fund fails (Figure 3). ${ }^{14}$

Figure 3. LOLR Funds vs. VMGH

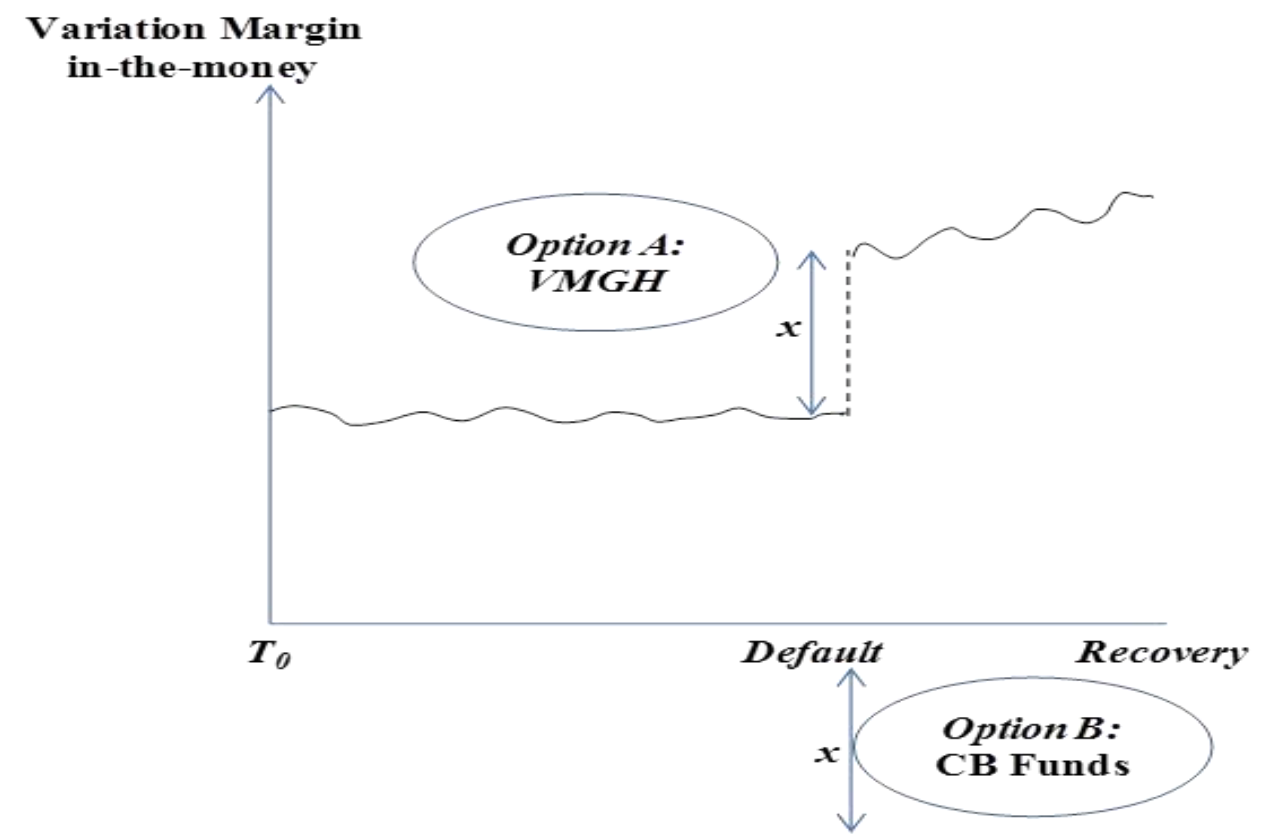

Source: Author's estimate.

The discussion here is about only about $\mathrm{x}$ i.e., $0 \leq \mathrm{x} \leq \mathrm{US} \$ 50$ billion not being paid to Blackrock due to the jump. In other words, if there were a default of a large bank, like Lehman, on a certain day (i.e., the day when the jump takes place), then "in the money" and "out of the money" positions till the previous day would be legally intact, as VMs would

\footnotetext{
${ }^{13}$ About 70 percent of OTC derivatives market is interest rate swaps.

${ }^{14}$ If the above scenario were reversed and Blackrock were the entity out of the money, the jump would probably not make it bankrupt because its AUM are large relative to the (up to) US\$50 billion loss. If US\$50 billion is to be posted as VM to the large hedge fund (who is in the money), then Blackrock's total AUM goes down by US\$50 billion; the hedge fund gets paid in full. There is no need for central bank liquidity. Also in this illustration the fact that n-2 players are not impacted by the jump event is only illustrative. So even if "in the money" and "out of the money" positions are split symmetrically (i.e., n/2 and n/2), the arithmetic of any jump not being paid is likely to work.
} 
have been mostly posted by the end of the previous day. ${ }^{15}$ In this illustration, $x$ is a shortfall that could have been modeled to augment the CCP waterfall but this jump event maybe the "tail of tail risk." "If waterfalls are not robust and not sufficient to cover the jump (due to limited liability of the CCP and the owners), any shortfalls that cannot be met from the waterfall will then likely be "put" to a central bank/Treasury without taking time to ascertain whether the jump has created a temporary liquidity gap in the CCP or whether it has made the CCP insolvent. ${ }^{17}$

A shock like this would normally trigger use of the waterfall. If the waterfall is robust (as CCPs claim they are) then the problem will be solved without recourse to any other mechanism. However, if the waterfall is not robust, then a VMGH would provide a sizable cushion that should be sufficient to cover most jump events, or, at least, delay the demand for government/central banks funds. As end-users will have to contribute in a VMGH (unlike the traditional waterfall structures), it is in their best interest to use CCPs with robust waterfall. ${ }^{18}$

With reference to Basel's bank capital requirement that limits uncapped liabilities, VMGH is a practical option. Margin is generally posted by the transfer of legal title from the participant to the $\mathrm{CM}$ and then from the CM to the CCP. As a legal matter, the CCP is the owner of the collateral, which would be difficult to extract from the insolvent entity if the CCP went bankrupt. In this case, the participants would become unsecured creditors. Segregation/ sweeping of in-the-money positions prior to a default will not impact the windfall gains ex post the default, as the gains have not yet been paid.

To avoid uncapped VMGH, all users (or via their CMs) should be willing to increase their share of IM and additional assessment/default fund at the waterfall level. And, to avoid moral hazard, all users should be part of the risk-management/ governance committee. For those users trying to cut corners on a waterfall and $\mathrm{VMGH}$, there may be jurisdictions that offer low IM at waterfall and no VMGH to grab market share, with some implied state guarantee to cover shortfall-see Box 1. Or, for one-directional users of OTC derivatives, such as pension funds, the windfall gain may be a real loss if the gain was a genuine hedge; in this case they can opt to clear in jurisdictions with no VMGH to skirt such losses.

\footnotetext{
15 Time zone margin posting issues are being discussed under regulatory working groups for such as FSB and CPSS/IOSCO.

${ }^{16}$ Since liquidity implies a temporary shortfall, these haircuts may be recouped when the book is balanced, either by liquidating the open positions of the defaulting member quickly to prevent further losses to the CCP; or if forced auctions are used (with some positions at a premium), they should include everyone- $\mathrm{CCP}, \mathrm{CMs}$, and end-users - despite the rhetoric that CCP relations to end-users is via CMs.

${ }^{17}$ Under U.S. law, only the U.S. Treasury can provide funds for a bailout.

${ }^{18}$ If waterfalls were indeed robust, there would be less concern about resolution/recovery of CCPs. However, there is a flurry of proposals that want to supplement waterfalls (JPMorgan white paper, September 2014).
} 


\section{Box. Central Bank Liquidity (when there is no uncapped VMGH)}

CCPs are required to maintain sufficient liquid resources to cover their obligations in a wide range of scenarios, including participant default. CCP rules will typically also include liquiditygenerating measures, including (liquidity) calls on members to replenish the default fund (required under the EMIR), a possible moratorium on payments by the CCP and a funding line from non-clearing member banks. For example, LCH.Clearnet rules allow a 30-day grace period preventing members from exercising termination rights following a failure by the CCP to make a payment. However, in a systemic crisis, the feasibility of attracting liquidity from the market is limited.

In jurisdictions that do not enforce uncapped VMGH, limited access to central bank liquidity or other forms of government support may be an alternative route. This applies to both the clearing participants as well as the CCP itself. There is considerable divergence of views internationally regarding the possible access of CCPs to central bank liquidity. Under Title VIII of Dodd-Frank, a CCP that is designated as a systemically important financial market utility would have access to Federal Reserve liquidity in "unusual or exigent circumstances" (i.e., emergency liquidity only) subject to approval by the Treasury. Additionally, if a CCP qualifies for orderly liquidation under Title II of Dodd-Frank, the Federal Deposit Insurance Corporation (FDIC), as the resolution authority, would have the power to finance any costs it incurs by borrowing from the Treasury up to a (specified) maximum amount.

CME's 1987 episode is of historical relevance: CB backstop was provided on the condition that funds be passed to CCPs through their member banks (thus increasing banks' liability to the Fed) and not directly to CCPs. In the United Kingdom (U.K.), there are no legal impediments to CCPs receiving central-bank liquidity; however, in practice, this may be limited to lender-of-last-resort facilities. In some jurisdictions, central-bank laws explicitly authorize liquidity to be provided to nonbank financial institutions (for example, Sweden and Switzerland), although there is no obligation to do so. Within the Eurosystem, national central banks may conduct credit operations with credit institutions and other market participants, which in principle include CCPs, although the practice varies among individual member states. The European Central Bank (ECB) requires that all eligible counterparties for credit operations have banking licenses in order to access to central bank liquidity.

The VMGH approach is a good proposal to separate the liquidity-versus-solvency ambiguity by providing a concrete measure of unfunded losses and a means of temporarily recouping the losses from non-defaulting in-the-money variation margin payments. It is argued that liquidity support should be available only for solvent, but illiquid CCPs; thus the solvency-versus-liquidity issues are not hard-wired in language. Also, VMGH bridges the gap where liquidity ends and when solvency starts, and thus should not be labeled only as a solvency tool. This is important since insolvency of (large) CCPs is unlikely as they will become systemic and too-big-to-fail; and in order to minimize the (ab)use of the "liquidity rubric," incorporating VMGH to the default waterfall of resources diminishes the risk of either recourse to central banks, or public treasuries and encourages market participants to police CCP risk management practices. 
VMGH is not a theoretical possibility. It is a mechanism already embedded in the covenants of several CCPS such as LCH.Clearnet and JSCC. ${ }^{19}$ Ideally the waterfalls should be made as robust as possible up front, and there should be provisions mandating that the waterfall resources are insufficient, any residual shortfall is recouped ex post via uncapped VMGH. As VMGH implies wider impact on unfunded losses on default, all participants should take a much greater interest in the governance and risk management of CCPs, protecting against moral hazard, complacency and the sacrifice of risk management for competitive advantage. This setup would reduce the need for central bank liquidity (or government support more generally). It would also give more time to resolve the complex legal issues surrounding the recovery (i.e., in CCPs domain) procedures of CCPs.

Modeling the contagion from defaults by one or more CMs within this new derivatives network is difficult and unchartered territory; the negative externalities may still not be contained by recovery tools and thus VMGH buffer can be useful. Preliminary research suggests contagion from CCPs to CMs from the use of VMGH will be contained.

Furthermore, the derivatives network continues to change due to the evolving regulations that bifurcates the derivatives market into CCPs and bilateral clearing. Thus, resolution procedures, or statutory powers outside CCP's domain, may be necessary if for example: (i) a CCP cannot return to a match book (e.g., failed auctions on defaulted CM portfolio despite $\mathrm{VMGH}$ ); or (ii) if losses stem from fraud or operational risk.

\section{Conclusion}

CCPs have, by regulatory fiat, become "too important to fail," and thus may demand government support in times of stress. This paper argues that the case for using public resources to support CPPs is not strong, and proposes mechanisms to reduce that risk. It advocates greater loss-sharing and robust waterfall structures in CCPs, especially given the large divergence of views in the governance and ownership structures. VMGH adds to the tools that a CCP may use to cover unfunded losses in the event of a CM default, and may contribute to better governance as both $\mathrm{CMs}$ and end-users will be interested to mitigate the risk of losses through better CCP risk management and governance. The paper also argues that if a VMGH is not sufficient to eliminate the risk of insolvency there may be a need for statutory powers to step in (Wendt, 2014). However, it is arguably preferable to secure this result ex ante, through the regulatory requirements relating to CCP rules.

Loss allocation choices arise when CCPs "robust" waterfalls are questioned due to potentially insufficient resources on default from either IM held against CM positions, or insufficient assets in default and guarantee funds (that are contributed by CMs and CCPs). As end-users increasingly get involved in recovery/resolution issues, and since some proposals may require "their skin in the game", they may be called on-via their CMs - to contribute towards the recovery of losses through $\mathrm{VMGH}$; this provides an extra buffer relative to margin calls only from CMs and CCPs.

${ }^{19}$ In the U.K., ICE Clear Europe (futures and options), CME's Clearing Europe, and LME have uncapped VMGH. 


\section{REFERENCES}

Bank for International Settlements, 2014, Semi-Annual OTC Derivative Statistics (various issues).

,2014, "Recovery of Financial Market Infrastructures," Committee on Payments and Market Infrastructures/ISOCO, October.

Bank of England, 2010, “Financial Stability Report,” December.

CPSS-IOSCO, 2013, “Principles for Financial Market Infrastructures,” July.

Elliot, David, 2013, “Central Counterparty Loss Allocation Rules,” Bank of England, Financial Stability Paper No. 20.

www.bankofengland.co.uk/research/Documents/fspapers/fs_paper20.pdf

Gibson, Matt, 2013, "Recovery and Resolution of Central Counterparties," Reserve Bank of Australia, December quarter bulletin. www.rba.gov.au/publications/bulletin/2013/dec/5.html

Heller, Daniel and Nicholas Vause, 2013, "Collateral Requirements for Mandatory Central Clearing of Over-the-Counter Derivatives," BIS Working Paper 373 http://www.bis.org/publ/work373.htm

International Monetary Fund, 2010, "Global Financial Stability Report," Chapter 3, April.

ISDA, IIF, The Clearing House, 2013, letter to CPSS-IOSCO, re: Recovery of Financial Market Infrastructures, October 11.

ISDA, 2013, CCP Loss Allocation at the End of the Waterfall. , 2014, Margin Surveys (various issues).

Securities Finance Monitor, 2014, “The Korea Exchange: A Cautionary Tale on CCP Waterfalls and Non-Defaulting Members Taking the Loss," March 18.

Singh, 2010, "Collateral, Netting and Systemic Risk in the OTC Derivatives Market," IMF Working Paper 10/99. www.imf.org/external/pubs/ft/wp/2010/wp1099.pdf

, 2012, Puts in the Shadows," IMF Working Paper 12/229. www.imf.org/external/pubs/ft/wp/2012/wp12229.pdf

, 2013, "New Regulations and Collateral Requirements-Implications for the OTC Derivatives Market, October for Swift Institute," SWIFT-Institute-Working-PaperNo-2012-004-New-Regulations-and-Collateral-OTC-Derivatives-Singh v7FINAL.pdf 1.13MB. 
Summe, Kimberly, 2012, “An Examination of Lehman Brothers' Derivatives Portfolio PostBankruptcy and Whether Dodd-Frank Would Have Made Any Difference," Hoover Institution, April.

http://media.hoover.org/documents/Kimberly-Summe-Dodd-Frank-20110421.pdf

Tucker, Paul, 2013, speech at Institute of International Finance, 2013 Annual Membership Meeting, Washington, DC, October 12, 2013. www.bis.org/review/r131015a.pdf

Wendt, Froukelien, 2014, “Central Counterparties: Addressing Their Too Important to Fail Nature,” IMF Working Paper. 